\title{
Leiomyoma of Female Urethra
}

\author{
Jariwala Suresh K.
}

Received: 14 February 2011 / Accepted: 8 August 2011/Published online: 30 August 2013

(C) Federation of Obstetric \& Gynecological Societies of India 2013

\section{Introduction}

Soft tissue tumor of female urethra is a rarity. We are describing a case of leiomyoma of urethra in a 28 -year-old female who presented to us with painful swelling and dysuria.

\section{Case Report}

A 28-year-old female presented with painful swelling of vulva and dysuria of 2 weeks duration. She had frequent painful micturition but no retention of urine. She had normal menstrual cycles. On examination (exam), a firm tender swelling of $2 \times 1.5 \mathrm{~cm}$ size was found protruding from external urethral meatus, obliterating lumen (Fig. 1). Anterior vaginal wall was normal and no purulent discharge on pressure. Rest of the examination was normal. A clinical diagnosis of soft tissue tumor of urethra was made.

Hematological, biochemical investigations, and ultrasonography of abdomen were normal.

Jariwala S. K.

Department of Urology, Rajah Muthiah Medical College

Hospital, Chidambaram 608002, Tamil Nadu, India

Jariwala S. K. (ه)

215/216, Arun Chambers, Tardeo Road, Mumbai 400034,

Maharashtra, India

e-mail: sjariwalak@yahoo.co.in
She was operated under spinal anesthesia. Cystoscopy revealed normal urinary bladder and swelling arising from dorsal aspect of midurethra (Fig. 2). A 16 FG Foley catheter was inserted. Urethral mucosa was elevated and swelling was removed after ligating the pedicle. Excess mucosa was trimmed and meatus was reconstructed dorsally (Fig. 3). Vagina was packed and was removed after $48 \mathrm{~h}$. Postoperative recovery was uneventful. Foley catheter was removed after 2 weeks. She was voiding normally with minimal stress incontinence (one pad per day). She was advised pelvic floor exercise and asked to follow up after 3 months.

Histopathology report was leiomyoma of urethra. The case is reported for its rarity.

\section{Discussion}

Soft tissue tumor of female urethra is a diagnosis by exclusion. One must consider followings in differential diagnosis.

Caruncle is an acute tender red swelling at meatus in elderly female. Diverticulum of female urethra present with tender swelling of anterior vaginal wall, dysuria, recurrent urinary tract infection, dyspareunia, and purulent discharge on pressure from meatus. Bartholin gland cyst is a non-tender cystic swelling of labia minora and majora. Infection is common giving rise to painful tender swelling. Gartner's duct cyst originates from remnant of mesonephric duct and gives rise to swelling of anterolateral wall of vagina. Valves and polyp are known to occur in male 


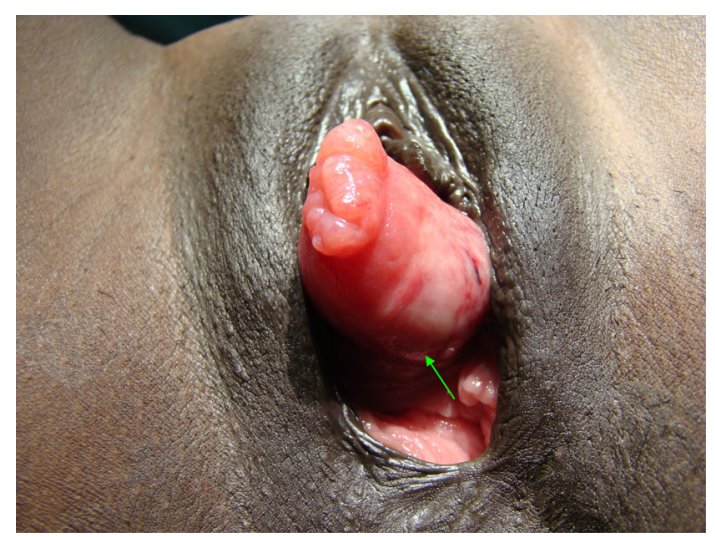

Fig. 1 Leiomyoma of urethra, preoperative. Arrow shows site of urethral lumen

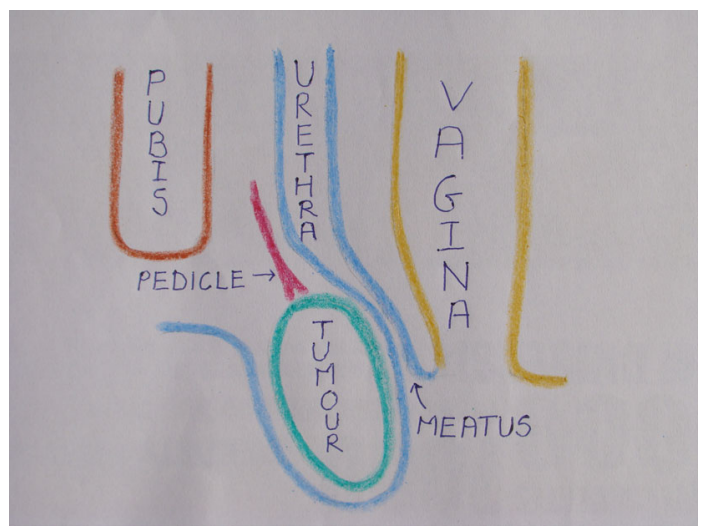

Fig. 2 Leiomyoma of urethra, cross-sectional view

urethra. Carcinoma of urethra present with bleeding or haematuria and indurations of anterior vaginal wall. Skene's gland cyst is a soft cystic swelling lateral or inferolateral to urethral meatus and does not communicate with lumen. Prostate-specific antigen may be raised and infection of the cyst can occur. Ectopic ureterocele prolapsing outside meatus is a cystic swelling in female child, confirmed by ultrasonography and cystoscopy. Our patient did not fit into any of these diagnoses.

Soft tissue tumor of female urethra is known to occur. Leiomyoma is the commonest soft tissue tumor [1]. It is more common in female than male. Five cases in male [2] and thirty cases in female [1] of leiomyoma of urethra are

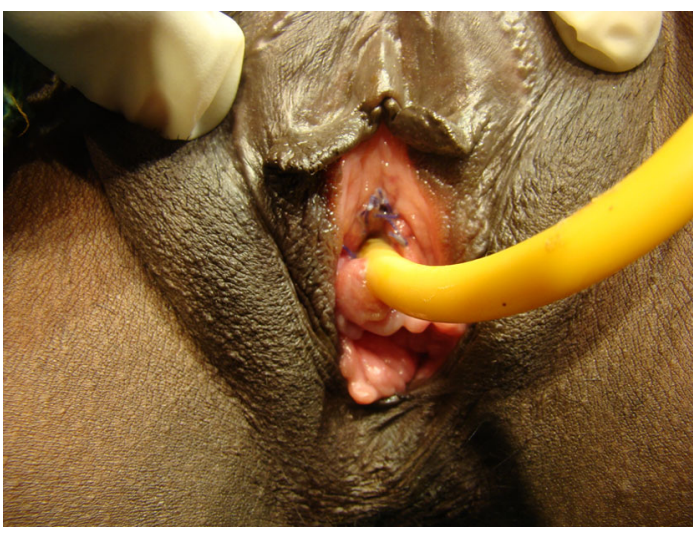

Fig. 3 Leiomyoma of urethra, postoperative view

described in the literature. Simple excision is treatment of choice. Tavassoli and Norris [3] described criteria for leiomyosarcoma. They are: size more than $5 \mathrm{~cm}$, more than 5 mitotic figures per 10 high power field, infiltrative margins, and severe atypical cells. Malignant change in leiomyoma of female urethra is not reported so far.

Stress incontinence developed in our patient after surgery as in others [4]. It was minimal and did not require further interference except physiotherapy.

\section{Conclusion}

Soft tissue tumor of female urethra is a rarity. Leiomyoma is the commonest soft tissue tumor. Simple excision is treatment of choice. Patient must be counseled about stress incontinence after surgery.

\section{References}

1. Reuter VE. Urethra. In: Bostwick DG, Cheng L, editors. Urologic surgical pathology. 2nd ed. China: Mosby Elsevier; 2008. p. 595-613.

2. Saad AG, Kaouk JH, Kaspar HG, et al. Leiomyoma of the urethra: report of 3 cases of a rare entity. Int J Surg Pathol. 2003;11:123-6.

3. Tavassoli FA, Norris HJ. Smooth muscle tumours of vulva. Obstet Gynecol. 1979;53:213-7.

4. Ozel B, Ballard C. Urethral and paraurethral leiomyomas in the female patient. Int Urogynecol J Pelvic Floor Dysfunct. 2006; 17:93-5. 